\title{
Cusp Doming Severity
}

National Cancer Institute

\section{Source}

National Cancer Institute. Cusp Doming Severity. NCI Thesaurus. Code C127549.

The qualitative measurement of the severity of doming of a cardiac cusp. 